\title{
The Loess Microstructure Indication Indexes for Paleoclimatic in Northwest of China
}

\author{
JIN DNEG ${ }^{12}$, YONGLI WANG ${ }^{3}$ \\ ${ }^{1}$ Lanzhou Institute of Seismology, CEA, Lanzhou 730000, \\ China \\ ${ }^{2}$ Geotechnical Disaster Prevention Engineering Technology \\ Research Center of Gansu Province, Lanzhou 730000, \\ China \\ ${ }^{3}$ Institute of Geology and Geophysics, Chinese Academy of \\ Sciences, Beijing 100029, China
}

Loess in northwest China is used to detect messages of monsoon climate evolution from its microstructure and to reflect different forming climatic conditions. The climatic indicators obtained from microstructure of loess, can reflect humidity, sand sedimentation and even subtle changes in temperature at its forming ages. The changes in humidity and temperature are also shown by the chemical indexes, such as the ratios of $\mathrm{Si} / \mathrm{Al}, \mathrm{Ca} / \mathrm{Mg}$ and $\mathrm{K} / \mathrm{Al}$ in big particles and the ratios of $\mathrm{Si} / \mathrm{Al}, \mathrm{Ca} / \mathrm{Mg}, \mathrm{Ca} / \mathrm{Fe}$ and $\mathrm{K} / \mathrm{Al}$ in fine clay particles. The index of sand sedimentation speed got from loess microstructure could be a new method to reflect sanddropping speed and loess deposition course. By analysis, it shown that the glacial maximum was a period with the most intense sanddropping and the post-glacial was the second sand-dropping frenquncy period. Meanwhile, in two periods, the high sand-dropping speed occurred in different areas of Gansu in China. In the post-glacial, sand-dropping concentrated in Qingbaishi, Lanzhou and Yuzhong, and then Lintao and Xicha-Gaolan; while in the glacial maximum, it mainly concentrated in Gaolan, and Mount Wuyi of Lanzhou. And it can be concluded that the glacial maximum experienced a great decline in temperature, while the postglacial experienced a severe aridity. Moreover, from the corresponding period loess microstructure, the loess forming climate of the glacial maximum was clearly showed the different from that of the post-glacial period. The glacial maximum loess was big particle and accumulate compactness, less cementation, which climate was intense wind, severe sand-dropping, coldness and more frequent rainstorm. While the post-glacial has smaller particle and accumulate relaxed, was forming of less intense sand-dropping, less aridity and was a little cold. The micro-structure of loess can also serve as a direct proof of climatic changes. For instance, the postglacial by large and loose particles, indicating a colder and drier climate than the glacial maximum; and the interglacial by fine particles and more crystalloids, indicating a warm and humid climate. 